\title{
The Influence of Intestinal Tract and Probiotics on the Fate of Orally Administered Drugs
}

\author{
Maja Stojančević ${ }^{*}$, Gordana Bojić ${ }^{2}$, Hani Al Salami ${ }^{3,4}$ \\ and Momir Mikov $1,3,5$ \\ 1'Department of Pharmacology, Toxicology and Clinical \\ Pharmacology, Faculty of Medicine, University of Novi Sad, \\ Serbia \\ ${ }^{2}$ Department of Microbiology, Institute of Public Health, \\ Faculty of Medicine, University of Novi Sad, Serbia \\ ${ }^{3}$ School of Pharmacy, Curtin Health Innovation Research \\ Institute, Curtin University, Perth WA, Australia \\ ${ }^{4}$ Faculty of Health Science, Central Queensland University, \\ Queensland, Australia \\ ${ }^{5}$ School of Pharmacy, University of Montenegro, Montenegro
}

\begin{abstract}
Although the liver has long been considered as a main organ responsible for drug metabolism, the role of the gut metabolizing enzymes and the gut microflora is becoming more profoundly evident in drug metabolism, absorption and overall efficacy. This review will explore various mechanisms by which the gut-microflora influences drug pharmacokinetics including biotransformation, bioactivation, and biodegradation as well as up- or downregulation of the epithelial transporters. The gut-luminal fluids, intestinal mucosa and gut microflora contain high concentrations of various enzymes which are responsible for the oxidation, hydrolysis and conjugation of drugs. Such metabolic reactions may lead to either drug over- or underdosing, which impacts the drugs efficacy and safety. The processes, by which the intestinal enzymes and gut-protein transporters influence drug pharmacokinetic parameters, will be detailed. Since the intestinal microflora plays an important role in physiological, nutritional, metabolic, and immunological processes in human body, there is currently some interest in the manipulation of its composition and activity by administering probiotics. This review will also examine the capacity of probiotics to interact with resident microbial community, affecting the respective enzymes or by providing their own specific enzymatic activities that may consequently change the bioavailability and pharmacological activity of concomitantly taken drugs.
\end{abstract}

\section{Introduction}

In general, the most common and desirable way of drug administration is the oral route, since it is the easiest and most convenient way of drug application, and many drugs are well absorbed by the gastrointestinal tract (Sastry et al., 2000). Factors that may influence intestinal absorption include the intestinal mucosa (Bourlioux et al., 2003), drug properties such as solubility and permeability, formulation, and physiological variables such as regional $\mathrm{pH}$ and intestinal motility. Clearly, good bioavailability and low intra- and inter-patient variability are desirable for oral drug delivery. Preclinical investigations of potentially new drugs should be designed to describe intestinal absorption mechanisms and to predict oral pharmacokinetics. The gastrointestinal tract functions as a bioactive membrane which prevents toxic and harmful xenobiotics from reaching the systemic circulation, while at the same time digesting and selectively absorbing essential nutrients, fluids, and electrolytes (Li and Hidalgo, 1996). Hence, physical barriers in the GIT as well as pharmacokinetic properties of the drug are the main factors that influence oral drug absorption.

Moreover, oral bioavailability of drugs is significantly influenced by the rate of in vitro dissolution, as well as body physiology such as the integrity of the gastrointestinal tract, physiological status, gastrointestinal motility, site of drug absorption, membrane transporters, presystemic drug metabolism, the effect of food or concomitant medication (Lee et al., 2001; Martinez and Amidon, 2002). For an orally administered drug to be absorbed it must be released from the dosage form, dissolved in the gastrointestinal fluids, remain intact in the gastrointestinal lumen and cross the epithelial membrane (Sousa et al., 2008). Anatomical, physiological, and biochemical factors that affect the dissolution, stability, absorption and presystematic elimination of drugs vary through the gastrointestinal tract (Lennernäs, 2010). Besides the role in drug absorption, intestine has a huge influence on drug biotransformation due to presence of numerous enzymes; in particular, those produced by the gut microflora (Rowland, 1988; Goldin, 1990; Laube et al., 2000).

One of the first recognized and mostly studied interactions of intestinal bacteria with drugs is in the case of anticoagulant therapy. Namely, intestinal bacteria has the role in the synthesis of vitamin K. Broad spectrum of antibiotics, by decreasing the population of bacterial flora in the gut, can remove an important source of this vitamin. Vitamin $\mathrm{K}$ deficiency may consequently enhance the anticoagulant therapy action causing clinically significant adverse events (Conly and Stein, 1992).

The aim of this review is to summarize the current knowledge regarding drug-presystemic metabolism in the gut, and elucidate the role of intestinal microbiota, enterocytes, transporters and various gut-enzymes on the fate of orally administered drugs. The review will also focus on probiotics as gut-conditioning agents, to modify the gut microfloral composition and activity and which brings about a change of the pharmacokinetics of administered drugs.

\section{Drug metabolism at intestinal level}

The liver is known to be the major organ responsible for drug metabolism and biotransformation. However, drug metabolism may start at the intestinal level, which can bring about a significant effect on the drugs efficacy and safety. The combined activity of drug transporters and metabolic enzymes present in luminal fluids and in the intestinal mucosa (Figure 1) have shown to significantly influence pharmacokinetic profile of a range of drugs and result in increased toxicity due to reduced metabolism, 


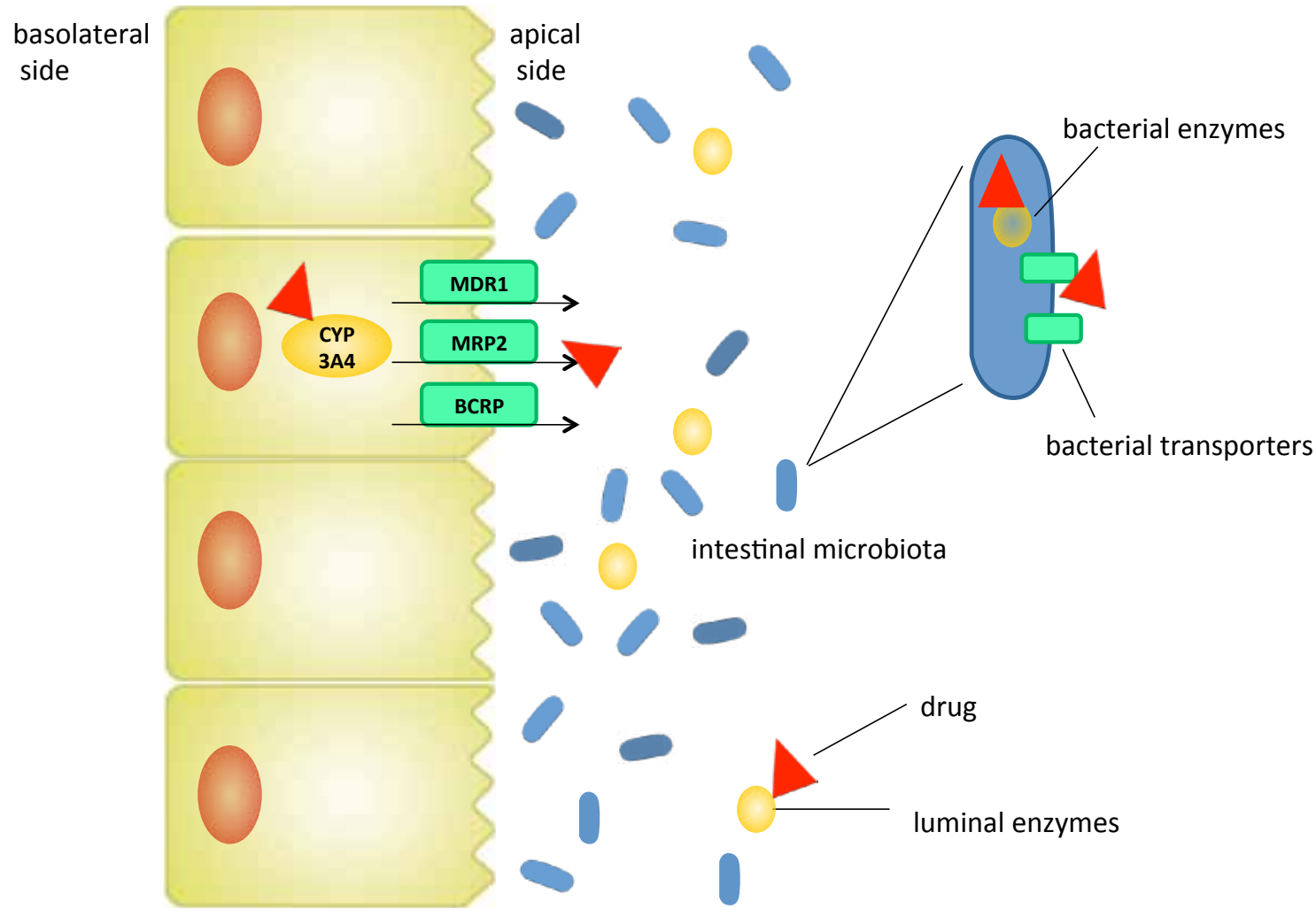

Figure 1. Fate of drugs at intestinal level. During the transit of drugs down the intestinal tract, they are exposed to enzymes present in intestinal lumen, enterocytes, and intestinal microflora. The combined activity of intestinal and bacterial transporters and these enzymes has a huge influence on a pharmacokinetic profile of drugs.

altered efficacy, increased production of toxic metabolites, and consequent adverse drug interactions (Gavhanea and Yadav, 2012).

\section{The role of intestinal microflora}

Intestinal microflora represents a complex ecosystem which consists of wide range of various microorganisms residing in or passing through the gastrointestinal tract (Gerritsen et al., 2011). The human microflora is composed of $10^{13}$ to $10^{14}$ microorganisms whose collective genome, the microbiome, contains at least 100 -fold more genes than the complete human genome (Marik, 2012). The microflora colonizes our skin, genitourinary, gastrointestinal, and respiratory tracts. By far the most heavily colonized organ is the gastrointestinal tract; the colon alone is estimated to contain over $70 \%$ of all the microbes in the human body (Sekirov et al., 2010). The human intestinal microflora comprises a diverse collection of species that are mostly bacterial (Wallace et al., 2011), some of which are nonculturable and therefore not well studied or fully characterized (Behnsen et al., 2013). The bacterial concentration in the ileum is between $10^{6} \sim 10^{8}$ bacteria per gram of intestinal contents gradually increasing to $10^{12}$ bacteria per gram of intestinal contents in the colon in human (Mikov et al., 2006). The majority of the human intestinal bacteria are composed of obligate anaerobes including species of the genera Bacteriodes, Clostridium, Lactobacillus, Bifidobacterium, Escherichia, and many others, together with a variety of yeasts and other microorganisms, forming a complex ecosystem that comprises at least 1000 species (Wilson and Nicholson, 2009). Each individual organism presents a specific "bacterial fingerprint," which is affected by a number of factors including host genotype, antibiotic treatment, diet and the maternal environment (Behnsen et al., 2013).

The microbiota plays a major role in health and disease (Clemente et al., 2012). The most important functions of intestinal bacteria include metabolism of many endogenous substances such as bilirubin, cholesterol, bile acids, steroid hormones, fatty acids, synthesis of vitamins $\mathrm{B}$ and $\mathrm{K}$, immune functions and fermentation of intestinal mucus produced by epithelial cells (Ferreira et al., 2011). Intestinal microflora provides additional enzymes and regulates the expression of genes involved in the utilization of carbohydrates and lipids, and in drugs bioconversion (Laparra and Sanz, 2010). Fermentation of carbohydrates by anaerobic bacteria produces short chain fatty acids (SCFA), mainly acetic, propionic, and butyric acids, which affect colonic epithelial transport, colonic metabolism, provide energy for heart, muscle, brain and kidney. In addition, intestinal bacteria contribute to lipid hydrolysis, protein breakdown with production of peptides and amino acids (Lenoir-Winjnkoop and Hopkins, 2003). Gut bacterial enzymes are also involved in the metabolism of cholesterol and bile acids. Intestinal microflora is able to reduce cholesterol to coprostanol and thus increasing its excretion in feces (Laparra and Sanz, 2010). Bacterial enzymes 
modify primary bile acids, cholic acid and chenodeoxycholic acid through dehydrogenation and dehydroxylation, resulting in formation of secondary bile acids, deoxycholic and lithocholic acids, respectively, which are reabsorbed and returned to the liver for further processing (Swann et al., 2010). The presence of intestinal bacteria is protective against exogenous, potentially pathogenic, microorganisms reducing the amount of available nutrients for invading pathogens. Additionally, commensal bacteria may produce antibacterial substances-bacteriocins that have an inhibitory effect of pathogenic bacterial growth (Al Salami et al., 2012b).

Metabolic reactions by intestinal microflora

Intestinal microflora can be considered as a system with huge metabolic capacity, qualitatively and quantitatively different from the body cells and organs. It is capable of carrying out a number of metabolic reactions resulting in production of metabolites required for the physiological activity or conversely in the inactivation, or even in the production of toxic products (Goldin, 1990). The presence of bacterial community and its metabolic activity play an important role in maintaining the host overall health and homeostasis (Wallace et al., 2011). However, despite broad investigation this complex system has not yet been fully clarified.

A number of factors such as availability and type of nutrients, some endogenous substances such as bile salts and glucuronides, colonic transit time, luminal $\mathrm{pH}$, sex, age of the host, disease, local immunity, production of bacterial metabolites, can modify the composition and the metabolic activity of the intestinal microflora (Rowland, 1988; De Preter et al., 2011). In many cases inter individual and intra individual differences in drug metabolism could be linked to variations in the metabolism of intestinal bacteria (Mikov, 1994). Interestingly, the microbial composition within one individual in healthy adults is shown to be highly stable throughout life once established, even though there is constant interaction between the bacteria within the gastrointestinal tract (Sekirov et al., 2010).

Drugs which may be exposed to intestinal microflora are those that are orally administered but suffer from low solubility, low permeability or both and reach the lower confines of the gastrointestinal tract, where the host microflora is the densest. Additionally, drugs which are rectally administered in the form of suppositories or enemas, as well as those that undergo enterohepatic cycling, or secretion and diffusion from the systemic circulation into the intestinal lumen may also come in contact with intestinal bacteria (Sousa et al., 2008). Several reviews have been published on intestinal microflora metabolism of drugs and other xenobiotics (Ilett et al., 1990; Mikov, 1994; Sousa et al. 2008; Wilson and Nicholson, 2009; Grundmann, 2010; Gavhanea and Yadav, 2012). While the liver is primarily responsible for metabolism via oxidation and conjugation producing polar and high molecular weight metabolites, the intestinal microflora is mainly involved in reductive and hydrolytic reactions generating non-polar low molecular weight byproducts (Sousa et al., 2008).

Hydrolysis is a very common metabolic reaction catalyzed by intestinal microflora. Hydrolysis of glycosidic linkage is one of the best-known examples of bacterial enzyme activity. The principal glycosidases are $\beta$-glucosidase and $\beta$-glucuronidase which hydrolyze the glycosidic bond of glycoside and glucuronide conjugates, respectively, to release parent compound (De Preter et al., 2011). It has been demonstrated that $\mathrm{pH}$ has a pronounced effect on the activities of bacterial $\beta$-glucuronidase and $\beta$-glucosidase. In human faecal bacteria, $\beta$-glucuronidase showed maximal activity at $\mathrm{pH} 6.0$, while the rat caecal bacteria expressed greatest activity at $\mathrm{pH}$ 8.0. On the other side, $\beta$-glucosidase activity decreased as $\mathrm{pH}$ increased from 6 to 8 (Mallett et al., 1989).

Anaerobic bacterial species have shown to be responsible for most of the $\beta$-glucuronidase activity in both the small and large intestine. Intestinal bacteria are responsible for deconjugation of morphine-6-glucuronide affecting its half-life (Stain-Texier et al., 1998). The removal of the polar conjugating group by intestinal bacteria may restore the active drug but also allows it to be reabsorbed and returned to its site of action. Thus, the intestinal microflora may delay drugs excretion of foreign compounds, enhance drugs bioavailability and prolong the action of drugs by promoting their enterohepatic recirculation (Martinez and Amidon, 2002; Sousa et al., 2008).

Hydrolysis of lactulose to lactic and acetic acid by intestinal bacteria contributes to its activation, stimulating water secretion into the intestinal lumen by lowering the $\mathrm{pH}$ of the intestinal content (Grundman, 2010).

One of the common reaction that occurs by enzymatic activity of intestinal microflora is azo reduction is of azocontaining compounds. The conversion of prontosil, the first commercially available antibacterial, to sulfonamide is one of the earliest examples on prodrug activation with the aid of azo-reductase enzymes by the large intestinal microflora. The reaction takes place in two steps, the formation of the hydrazo compound, followed by the reductive cleavage of the nitrogen bond (Ünsalan et al., 2011).

In addition, intestinal microflora plays a crucial role in the metabolism and pharmacokinetics of sulfasalazine affecting efficacy of the drug in rheumatoid arthritis and inflammatory bowel disease (IBD). The molecule of sulfasalazine contains 5-aminosalicylic acid (5-ASA) and sulfapyridine (SP) linked together by an azo bond (Mikov et al., 2006). Only a small fraction of orally administered sulphasalazine is absorbed. The majority of the ingested dose travels down the small intestine to the colon where it undergoes bacterial azo reduction yielding two major metabolites SP and 5-ASA (Houston et al., 1982). SP appears to be the active moiety in rheumatoid arthritis due to its antibacterial and immunomodulating effects, whereas 5-ASA is the active agent in IBD (Mikov et al., 2006).

Furthermore, the common targets for bacterial reduction reactions are nitro groups which results in primary amine metabolites as has been observed for nitrazepam, clonazepam, and misonidazole (Grundmann, 2010). Takeno and Sakai (Takeno and Sakai, 1991) proved that the intestinal microflora plays an important role in the reductive metabolism of nitrobenzodiazepine drug, nitrazepam, suggesting that the teratogenicity of nitrazepam may be related to this kind of nitro reduction. Incubation of clonazepam with rat-intestinal lumen contents gave almost complete reduction of clonazepam to 7-aminoclonazepam (Elmer and Remmel, 1984).

Chloramphenicol, a potent inhibitor of protein synthesis, has bacteriostatic activity against most pathogens but is 
bactericidal for Haemophilus influenzae, Streptococcus pneumoniae, and Neisseria meningitides (Nitzan et al., 2010). It contains a nitrobenzene group and an amide of dichloroacetic acid. After incubation with intestinal bacteria, a number of reactions can be detected such as a conversion of a nitro group to a primary aromatic amine and hydrolysis of the amide linkage (Holt, 1967).

Metronidazole is an antimicrobial agent that has been used in clinical medicine for more than 45 years and is still successfully used for the treatment of trichomoniasis, amoebiasis, and giardiasis (Löfmark et al., 2010). It is a 5-nitroimidazole derivative which is almost completely metabolized in liver by side-chain oxidation and glucuronide formation, but a small amount of reduced metabolites, including ring cleavage products such as $\mathrm{N}$-(2-hydroxyethyl)oxamic acid and acetamide, are formed by anaerobic bacteria in gut (Koch and Goldman, 1979).

Zonisamide is an anticonvulsive drug clinically used for the treatment of epilepsy. Besides the biotransformation in the liver to 2-sulfamoyacetylphenol by reduction of benzisoxazole ring Kitamura et al. showed that intestinal bacteria has a significant role in the reductive metabolism of zonisamide, to 2-sulphamoylacetylphenol in-vivo (Kitamura et al., 1997).

An example for reductive metabolism by intestinal bacteria is observed in the case of cardiac glycoside drug digoxin, which undergoes significant metabolic conversion in many patients to cardioinactive metabolites in which the lactone ring is reduced (Saha et al., 1983).

The intestinal microflora plays a role in the reduction of some sulfur compounds to sulfite metabolites. Study conducted by Strong et al. (Strong et al., 1984) indicated that sulphoxide-containing drugs such as non-steroidal anti-inflammatory analgesic, sulindac, and uricosuric agent, sulfinpyrazone are reduced by intestinal bacteria to sulfide metabolite in humans.

In addition, the intestinal bacteria expresses various enzymes involved in processing of glutathione conjugates of xenobiotics excreted in the bile, reactions of decarboxylation, dehydroxylation, dealkylation, dehalogenation, deamination etc. These microbial enzymes may act in concert with those of the liver (Wilson and Nicholson, 2009).

Approaches for examining microflora diversity and drug metabolism by intestinal microflora

There are several approaches which are commonly used to examine the intestinal microflora diversity, activity and their role in metabolism of drugs and other xenobiotics. One possible way is to determine the effect of direct action of gut contents incubations. Some studies examined the action of pure cultures, mixed cultures, continuous cultures and cell-free bacterial products (Mikov, 1994). Since a large fraction of the intestinal microflora remains uncultivated on that way, for a more accurate analysis of the its compositional diversity, different molecular techniques are used, including quantitative polymerase chain reaction ( $\mathrm{qPCR}$ ), temperature or denaturing gradient gel electrophoresis (TGGE or DGGE), terminal-restriction fragment length polymorphism (T-RFLP) and fluorescent in situ hybridisation (FISH) (Gerritsen et al., 2011). In addition, it is possible to get insight into the role of intestinal bacteria in drug metabolism via studying drug metabolism after oral and parenteral administration, difference between control animals and animals treated with antibiotics or difference between control and gnotobiotic animals. By determining the expression of enzyme activity by intestinal bacteria, the role of specific enzymes may be revealed (Mikov, 1994).

Gut wall/mucosal and luminal enzymes in drug metabolism The discovery of wide spectrum of metabolic activities that occurs in the intestine, due to presence of various phase I and II enzymes for oxidation, hydrolysis, and conjugation have led to renewed interest in the process of gut wall metabolism and its implications for drug therapy (llett et al., 1990; Krishna and Klotz, 1994; Pang, 2003; Thelen and Dressman, 2009)

A part of its metabolic capacity seems to be in close relation with the presence of the cytochromes. The most common P450 cytochrome subfamily expressed in the mucosa of the small intestine is CYP3A, which represents the major intestinal CYPs, accounting for approximately $80 \%$ of the CYP content in human enterocytes, followed by CYP2C9 (15\%) (Bezirtzoglou, 2012). CYP1A cytochrome, which metabolizes acetaminophen, caffeine and theophylline (Wacher et al., 2001), is expressed in the duodenum, together with less abundant levels of CYP2C8-10 and CYP2D6 (Bezirtzoglou, 2012). The distribution of most CYP enzymes is not uniform along the human gastrointestinal tract, being generally higher in the proximal regions of the small intestine (Thelen and Dressman, 2009).

Although the concentrations of CYP, normalized for the entire intestine, are estimated to be 20-to 200-fold lower than those found in the liver (Deferme et al., 2008), immunohistochemical studies have shown that small intestinal concentrations of CYP3A4 are approximately $80-100 \%$ of the CYP3A4 concentration in the liver (Wacher et al., 2001). Oral pharmacokinetic studies have suggested that the gut wall metabolism of drugs by CYP3A4 has a significant role in total first-pass effect of many drugs (Dresser et al., 2000) such as verapamil (Fromm et al., 1996), midazolam (Thummel et al., 1996), felodipine (Bailey et al., 1991) and cyclosporine (Wu et al., 1995).

Of particular importance is the synergistic function of P-glycoprotein (P-gp) and CYP3A4 in the small intestine, which may limit oral drug bioavailability of a wide variety of compounds (Martinez and Amidon, 2002). That they may act synergistically is suggested not only by their joint presence in small intestine enterocytes but also by the significant overlap in their substrate specificities and the poor oral bioavailability of joint substrates (Kivistö et al., 2004). Thus, the gut may play a significant role in drug-drug interactions as a result of the inhibition or induction of P450s and/or efflux transporters (Lee et al., 2001).

Esterases represent another important group of metabolizing enzymes present in the gut. In order to overcome the poor membrane permeability, poor solubility or insufficient chemical stability, many pharmacologically active compounds are applicated in form of esters which have to be converted to active drug after absorption by the intestine (Deferme et al., 2008). However, the luminal and mucosal esterase activity may cause a presystemic activation and thus a decreased absorption of the lipophilic prodrug. Carboxylesterases catalyze the hydrolysis of a variety of ester-containing and amide-containing endogenous compounds to their respective free acids, having important roles in the inactivation of a variety of 
structurally diverse drugs and the activation of prodrugs (Imai et al., 2005). Carboxylesterases are mainly responsible for the hydrolysis of xenobiotics such as propranolol ester derivatives, acetylsalicylic acid, and p-nitrophenyl acetate in mammalian intestinal microsomes (Masaki et al., 2007). Fosamprenavir is the phosphate ester prodrug of the HIV-1 protease inhibitor amprenavir, and is rapidly and extensively converted to amprenavir in the intestinal lumen and in the enterocytes after oral administration mainly by alkaline phosphatases, resulting in an increased intestinal absorption (Furfine et al., 2004; Wire et al., 2006).

Besides esterases, luminal enzymes include also peptidases which contribute to poor oral bioavailability of many peptidyl drugs such as insulin, calcitonin, thyrotropin releasing hormone (Gavhanea and Yadav, 2012).

At the other side, a wide range of phase II enzymes (UDP-glucuronosyltransferases, sulfotransferases, acetyl transferases, glutathione S-transferases, methyltransferases) are found in the human intestinal mucosa, contributing to the presystemic metabolism of many drugs (Wacher et al., 2001). Interestingly, some phase II conjugation enzymes, especially sulfotransferase activities are approximately $250-300 \%$ higher in the jejunum compared to the liver (Grundman, 2010).

\section{Influence of intestinal and bacterial transporters on drug pharmacokinetics \\ Intestinal transporters}

Since all orally administered drugs must pass through the gut wall mucosa during absorption, before reaching the capillaries that lead to the portal vein, the intestine plays an important role in regulating the extent of drug absorption (Pang, 2003). The mucosal barrier consists of polarized enterocytes joined by tight junctions. In these cells many drug transporters have been described (Estudante et al., 2012). Membrane transport proteins play important roles in the influx and efflux of various nutrients, xenobiotics and cell signalling molecules in the cell (Kim, 2006). Transporter expression in the intestine affects how much of a drug will reach the systemic circulation after an oral administration, thus suggesting that factors which affect their expression and function, may change pharmacokinetics, efficacy and safety profiles of drugs. Furthermore, clinical pharmacokinetic drug-drug interaction studies have shown that transporters often work together with drug-metabolizing enzymes in drug absorption and elimination (Giacomini et al., 2010). Numerous drug transporting membrane proteins have been described in intestinal tissues, and most of them belong to two major classes of transporters, the ATP-binding cassette $(A B C)$ and solute carrier (SLC) family (Estudante et al., 2012).

$A B C$ transporters determine oral bioavailability of many drugs, tissue penetration, cellular accumulation and excretion, influencing basic pharmacokinetic parameters reflected in the plasma concentration time profile (Szakács et al., 2008). ABC proteins are primarily located in the cytoplasmic membrane of bacteria and in membranes in eukaryotes. While prokaryotic $A B C$ transporters can be either exporters or importers, eukaryotic family members are exclusively exporters (Sharom, 2008) which extrude a variety of structurally diverse drugs, drug conjugates and metabolites, and other compounds from the cell (Schinkel and Jonker, 2003).
The most investigated $A B C$ transporters at the intestine are multidrug resistance protein (MDR1, P-gp; gene $A B C B 1$ ), multidrug resistance-associated proteins (MRP; gene $A B C C s$ ) and breast cancer resistance protein (BCRP; gene ABCG2) (Englund et al., 2006) which have a major impact on the pharmacological behavior of most of the drugs in use today. These efflux mechanisms across the intestinal barrier may decrease the intracellular concentration of the drugs and their metabolites which were shown to be substrates of such efflux carriers such as antibiotics, statins, anticancer and cardiac drugs, HIV protease inhibitors, immunosuppressants and others, by actively pumping them out of the cells (Englund et al., 2006, Lennernäs, 2010).

While P-gp and BCRP can export both unmodified drugs and drug conjugates, MRP1 has the role in export of glutathione and other conjugates and unconjugated drugs together with free glutathione. All three exhibit overlapping substrate specificity (Sharom, 2008).

The best characterized of these proteins, P-gp, has a very broad specificity for substrates, as the protein is able to transport the number of chemically and pharmacologically unrelated drugs such as calcium channel blockers (verapamil, nifedipine), the immunosupressive agents (cyclosporine, tacrolimus, sirolimus), HIV protease inhibitors (indinavir, ritonavir), analgesics (morphine), cardiac glycosides (digoxin), antihelminthics (ivermectin), glucocorticoids (dexamethasone) antibiotics (erythromycin) and H2-receptor antagonists (Sharom, 2008). Many cytotoxic anticancer drugs (vincristine, etoposide, doxorubicin, daunorubicin, paclitaxel) are transported by P-gp, which was shown to be overexpressed in human cancer cells leading to the failure of chemotherapy (Schinkel and Jonker, 2003).

Although the chemical structures recognized by P-gp are not fully determined, favoured $P$-gp substrates appear to be cationic, hydrophobic molecules, with at least two planar rings and a molecular weight of 400-1500 (Lennernäs, 2010). Therefore, the bioavailability of many orally administered drugs is limited by P-gp activity (Schinkel and Jonker, 2003). The level of expression and functionality of P-gp can be modulated by inhibition and induction, which can influence the pharmacokinetics, efficacy, safety or tissue levels of P-gp substrates (Giacomini et al., 2010).

The family of SLC transporters is involved in the efficient absorption of a wide range of structurally different drugs, carcinogens and other toxins. These transporters include, solute carrier organic anion transporter families (OATP subfamilies; gene SLCO), solute carrier peptide transporter family (PEPT1; gene SLC15A1) and organic cation/zwitterion transporters (OCTNs; gene SLC22) (Sugiura et al., 2006; Oostendrop et al., 2009). Some of the drug molecules transported by SLC transporters include $\beta$-lactam antibiotics such as penicillins and cephalosporins, the anticancer agent bestatin, angiotensin-converting enzyme inhibitors such as captopril, and the ester prodrugs enalapril and fosinopril (Oostendorp et al., 2009).

\section{Bacterial transporters}

Beside enzymatic degradation or modification of drugs, one of possible mechanisms that intestinal bacteria may influence drug pharmacokinetics is drug transport by bacterial membrane proteins. Bacterial transporters have been mostly investigated in terms of the resistance to the 
toxic effects of antibiotics and other drugs (Mathur and Singh, 2005; Margolles et al.; 2006, Li and Nikaido, 2009). Namely, bacteria have developed various mechanisms that protect them from environmental toxins, antibiotics and other drugs (Ahmed et al., 1995). One of the most widespread mechanisms that ensures a significant level of drug resistance or tolerance being specialized membranebound efflux pumps that have been found to be involved in the export of a wide range of antimicrobial compounds (Grkovic et al., 2002).

There has been a growing list of multidrug and drugspecific efflux pumps characterized from bacteria of human gastrointestinal tract ( $\mathrm{Li}$ and Nikaido, 2009). In contrast to specific drug efflux transporters, which show high selectivity for a given drug or class of drugs, the so-called multidrug transporters may transport a wide range of structurally unrelated compounds (Ahmed et al., 1995). Based on their sequence similarity, bacterial drug efflux systems have been broadly classified into two groups: $A B C$ transporters and the secondary transporters. The class of secondary transporters can be subdivided into distinct families of transport proteins: the major facilitator superfamily (MFS), the multidrug and toxic compound efflux (MATE), resistance-nodulationdivision (RND) and the small multidrug resistance (SMR) superfamily (Putman et al., 2001; Kourtesi et al., 2013). Transporters belonging to $A B C$ superfamily couple the energy released from ATP hydrolysis to drive drug efflux (Davidson and Chen, 2004), whereas secondary multidrug transporters utilize the transmembrane electrochemical gradient, typically the proton motive force (Putman et al., 2001). Representatives of all groups are expressed in mammalian cells (Kourtesi et al., 2013).

Contrary to eukaryotes where MDR transporters mostly belong to the $A B C$ family, the vast majority of bacterial multidrug efflux systems characterized up to now belongs to secondary transporters (Putman et al., 2001) and just a few of them, such as LmrA and LmrCD from Lactococcus lactis (van Veen et al., 2000), HorA from Lactobacillus brevis (Sakamoto et al., 2001) and BmrA from Bacillus subtilis (Orelle et al., 2003) belong to the ABC type family. The family of MFS transporters represents the largest group of secondary active transporters with well characterized multidrug pumps, including Bmr and Blt of Bacillus subtilis and LmrP of Lactobacillus lactis (Li and Nikaido, 2009).

Bacillus subtilis is one of the microorganisms that contains the highest amount of putative MDR transporters in its genome (Paulsen et al., 2001). The genome of Bacillus subtilis encodes for at least $78 \mathrm{ABC}$ transporters that have been split in 38 importers and 40 exporters (Torres et al., 2009). Several multidrug pumps including Bmr, Blt, Bmr3 and $\mathrm{LmrB}$ have been described in Bacillus subtilis ( $\mathrm{Li}$ and Nikaido, 2009). Bmr and Blt are two highly similar MFS MDR transporters that share $51 \%$ sequence identity and confer very similar levels of resistance to an identical range of toxic substances when overexpressed (Grkovic et al., 2002). Bmr is structurally similar to tetracycline transporters (25\% sequence identity) but does not cause tetracycline efflux. Instead, overexpression of either transporter in Bacillus subtilis leads to a similar increase in resistance to a variety of toxic substances, including such structurally diverse compounds as ethidium bromide, rhodamine and acridine dyes, tetraphenylphosphonium, puromycin, chloramphenicol, doxorubicin, and fluoroquinolone antibiotics (Ahmed et al., 1995). BmrA, a functional ABC transporter in Bacillus subtilis, is homologous to mammalian P-gp and to LmrA of Lactococcus lactis ( $\mathrm{Li}$ and Nikaido, 2009).

In silico analysis of the genome of non-pathogenic, Gram-positive Lactococcus lactis suggests the presence of 40 putative drug transporters including LmrA, LmrCD (ABC transporters) and LmrP (MFS) (Li and Nikaido, 2009). A protein in Lactococcus lactis, LmrA, mediates drug and antibiotic resistance by extruding amphiphilic compounds from the inner leaflet of the cytoplasmic membrane. Interestingly, LmrA is a structural and functional homolog of the mammalian multidrug resistance $\mathrm{P}$-gp and both proteins have a very similar drug and modulator specificity. It was demonstrated that this type of multidrug-resistance efflux pump is conserved from bacteria to man (van Veen et al., 2000). An ABC multidrug exporter HorA, which amino acid sequence is $53 \%$ identical to that of LmrA in Lactococcus lactis, is involved in resistance of Lactobacillus brevis to hop compounds (Sakamoto et al., 2001). Expression of the $\operatorname{mdt}(\mathrm{A})$ gene in Lactococcus lactis decreased susceptibility to macrolides, lincosamides, streptogramins, and tetracyclines (Perreten et al., 2001)

Like other constituents of intestinal microflora, Bifidobacterium has developed mechanisms to tolerate different factors in the intestinal niche, such as bile salts and antibacterial peptides. Drug efflux is probably a major mechanism for such tolerance or resistance ( $\mathrm{Li}$ and Nikaido, 2009). BbmR is a membrane protein from Bifidobacterium breve which is able to confer resistance to macrolides and exhibited characteristics reminiscent of MDR proteins. Its homologue in Bifidobacterium longum, named Ctr, was also found to confer resistance to several antibiotics and to transport radioactive cholate (Margolles et al., 2006).

\section{The role of probiotics in drugs pharmacokinetics}

Because the intestinal microflora plays an important role in physiological, nutritional, metabolic, and immunological processes in the human body, there is currently some interest in the manipulation of its composition and activity by antibiotics, probiotics, prebiotics and synbiotics (Gareau et al., 2010). In this chapter, we focus at probiotic approach which aim is to repair the deficiencies in intestinal microflora due to improper diet, radiotherapy, antibiotic treatment or other stressful conditions, and to restore the 'balance' of the intestinal microflora and its protective effect (Ferreira et al., 2011).

According to the definition formulated by the World Health Organization (WHO) probiotics are 'live microorganisms which, when administered in adequate amounts, confer a health benefit on the host' (Joint FAO/WHO Working Group, 2002). Combinations of different bacterial strains can be used as probiotics, but certain bacterial genera, namely Lactobacillus (Lactobacillus acidophilus, Lactobacillus casei, Lactobacillus plantarum, Lactobacillus reuteri, Lactobacillus rhamnosus, and Lactobacillus salivarius) and Bifidobacterium (Bifidobacterium bifidum, Bifidobacterium breve, Bifidobacterium longum, and Bifidobacterium lactis), which have a long and safe history in the manufacture of dairy products, are common choices included in probiotic products (Fooks and Gibson, 2002; Kleerebezem et al., 2009). Bifidobacteria and lactobacilli are Gram-positive 
lactic acid-producing bacteria constituting a major part of the microflora in the human gastrointestinal tract, in which they developed soon after birth (Orrhage and Nord, 2000). Less commonly used are the bacterial strains of Enterococcus (Enterococcus faecium and Enterococcus faecalis), Bacillus (Bacillus subtilis and Bacillus cereus var. toyoi), Streptococcus (Streptococcus thermophilus and Streptococcus salivarius), Lactococcus, and Escherichia among others. The yeast Saccharomyces boulardi is also used as a human probiotic, in the forms of capsules or powders rather than in food form (Pavlovic et al., 2012). Probiotic species differ in terms of their metabolic activity, bioavailability and mode of action (Gillor et al., 2008).

Probiotics have been demonstrated to have healthbeneficial effects in a wide range of conditions including infections, allergies, gastrointestinal and metabolic disorders (lannitti and Palmieri, 2010; Al Salami et al., 2012b). Although the exact manner in which probiotics may achieve their effects is still unknown, some mechanisms can be suggested, such as the release of antibacterial substances (bacteriocins and bacteriocin-like inhibitory substances), secreting non-specific antimicrobial substances, induction of the production of antimicrobial compounds (defensins) by the host, direct enzymatic activities of probiotics within the gut lumen, reduction of luminal $\mathrm{pH}$, inhibition of bacterial adherence, competition for nutrients and immune clearance (Fooks and Gibson, 2002; Gillor et al., 2008). There is growing evidence that the same effects might be even achieved with dead probiotic bacteria or just integral components of the bacterial cell such as peptidoglycan fragments or DNA (Oelschlaeger, 2010).

Modification of the composition and metabolic activity of intestinal microflora by probiotics

By interacting with the resident microbial community, modulating its composition and activity affecting the respective enzymes or by providing their own specific enzymatic activities, probiotics may affect drugs pharmacokinetics (Gibson and Roberfroid, 1995). However, up to this date, there is a little data about the influence of probiotics on concomitantly taken drugs. Probiotic bacteria may influence the expression and functionality of various proteins and membrane transporters of other bacteria in gut, via changing the gut concentrations of certain polypeptides. This can be caused by the induction or suppression of membrane-transporters or by the process of direct-signalling (Al Salami et al., 2012b).

There is good evidence in humans that consumption of Lactobacillus probiotic strains increases the gut populations of lactobacilli (Rabot et al., 2010). In general, species of Bifidobacterium and Lactobacillus, which are commonly used as probiotics, have low activities of metabolizing enzymes such as azoreductase, nitroreductase and ß-glucuronidase, by comparison to other major anaerobes in the gut such as Eubacteria, Bacteroides, and Clostridia (Burns and Rowland, 2000). In a study with rats, supplementation with live Lactobacillus acidophilus for 3 days significantly suppresses the activities of ß-glucuronidase and ß-glucosidase in the colon (Cole et al., 1989). Examining effects of the probiotic Lactobacillus plantarum and the combination of probiotic and prebiotic, on counts of lactobacilli and coliforms and bacterial enzymatic activities in faeces of rats, Strojný et al. showed a statistically significant decrease in the activities of $\beta$-galactosidase, $\beta$-glucuronidase and $\alpha$-glucosidase, confirming the positive impact of lactobacilli on the presence of microorganisms in the intestinal ecosystem (decreasing the count of total coliforms and increasing lactobacilli) (Strojný et al., 2011). Goldin and Gorbach (Goldin and Gorbach, 1984) showed a significant decrease in fecal ß-glucuronidase, nitroreductase, and azoreductase activity after intake of lactobacillus in human volunteers. Reductions of 2- to 4-fold in the activities of the three fecal enzymes were observed only during the period of lactobacilli feeding. Furthermore, it was found that Bifidobacterium adolescentis SPM0212 inhibited fecal enzymes, including a-glucuronidase, a-glucosidase, tryptophanase, and urease (Kim et al., 2008). Similar results were obtained by Spanhaak et al. (Spanhaak et al., 1998) who reported a significant decrease in the activity of fecal ß-glucuronidase and ß-glucosidase activity in a group of twenty healthy male subjects given Lactobacillus casei. Besides, the consumption of Lactobacillus casei resulted in an increase of the Lactobacillus and Bifidobacterium counts in the faeces.

Mikov et al. (Mikov et al., 2006) proved that administration of probiotics significantly enhance bacterial mediated reduction of sufasalazine to SP and 5-ASA in colon content. Therefore, probiotics (Lactobacillus acidophilus, Bifidobacterium lactis, and Lactobacillus rhamnosus) can be used to modify the enzymatic activity of intestinal bacteria by increasing azoreductase activity, thereby producing more extensive metabolism of sulfasalazine. This could be particularly important in patients with dysbiosis consequent on antibiotic therapy or severe diarrhea. Recently Lee et al. (Lee et al., 2012) confirmed a significant increase in azoreductase activity in ex vivo colon contents with a corresponding increase in sulfasalazine metabolism, after treatment of rats with oral doses of a mixture of the three probiotics.

Human studies have shown that the impact of probiotics on the activity of bacterial enzymes is strain specific (Goossens et al., 2003). This may partly explain the fact that probiotic interventions showed different effects on ß-glucosidase activity, probably due to application of different lactobacilli or bifidobacteria strains as probiotic, as well as differences in amount or the duration of the probiotic intake (De Preter et al., 2011).

\section{Other probiotic impacts in intestinal tract}

Probiotics may functionally modulate the intestinal epithelial barrier of the host by different mechanisms, including prevention of pathogenic bacterial growth, blocking of pathogen binding to or penetration of mucosal surfaces, stimulation of mucosal barrier function, and altering immunoregulation (Stojancevic et al., 2012).

The antimicrobial activity of probiotic bacteria has been associated with the production of metabolites such as organic acids (lactic and acetic acid) with a resulting decrease in $\mathrm{pH}$ of the surrounding environment, which may directly inhibit the growth of harmful organisms, hydrogen peroxide, carbon dioxide, ethanol, diacetyl, acetaldehyde, as well as bacteriocins or bacteriocin-like substances (Suskovic et al., 2010). The bacteriocin family includes a heterogeneous group of proteins in terms of size, biochemical properties, microbial target and mode of action. Generally, they are most active against closely 
related bacterial species occupying the same ecological niche and thus have a relatively narrow killing spectrum (Gillor et al., 2008). The bacteriocin gains entry into the target cell by recognizing specific cell surface receptors and then kills the cell by several mechanisms: forming ion-permeable channels in the cytoplasmic membrane, inhibition of protein synthesis through the specific cleavage of $16 \mathrm{~s}$ rRNA, nonspecific degradation of cellular DNA, or cell lysis. There are two main groups of bacteriocins: those produced by Gram-positive and Gram-negative bacteria (Riley and Wertz, 2002).

During intestinal transit, probiotics produce effective enzymes (sucrase, protein phosphatase, leucine aminopeptidase, proteases, etc.), proteins, polyamines, mainly spermine and spermidine, and SCFA such as butyrate that regulate gene expression and protein synthesis. These metabolites secreted by probiotic bacteria exert various effects via a cell signaling pathway (Buts and De Keyser, 2006; Raheja et al., 2010).

Studies demonstrated that probiotics $B$. infantis, E. coli 1917 , and $L$. plantarum increase the expression of tight junction proteins such as zonula occludens (ZO)-1, ZO2 , and occludin, thus improving epithelial barrier function both in vivo and in vitro (Raheja et al., 2010). Besides, two soluble proteins from Lactobacillus rhamnosus GG, p75 and $\mathrm{p} 40$, are demonstrated to promote cell survival and growth in human and mouse colon intestinal epithelial cells. These proteins inhibit TNF-a-induced cell apoptosis by activation of the anti-apoptotic factor Akt and protein kinase B. Consequently, TNF-induced colon epithelial damage was significantly reduced by both, p75 and p40. Additionally, they inactivate the pro-apoptotic p38 mitogen-activating protein kinase signalling pathway in epithelial cells (Yan et al., 2007). All these effects of probiotics are suitable for strengthening the gut epithelial barrier (Oelschlaeger, 2010).

Some probiotics may modulate the in vitro expression of pro and anti-inflammatory molecules in a strain-dependent manner. For instance, Lactobacillus sakei induces the expression of interleukin (IL)-1 $1 \beta$, IL-8 and tumor necrosis factor (TNF)- $\alpha$, whereas Lactobacillus johnsonii stimulates the production of transforming growth factor (TGF)- $\beta$ in Caco-2 cells (Delcenserie et al., 2008).

Furthermore, a probiotic supplementation seems to influence transport properties of small intestine epithelium. Buts et al. showed that the expression of the sodium/glucose cotransporter-1 (SGLT-1) in brush border membranes of resected rats treated with Saccharomyces boulardii was significantly increased compared with resected controls (Buts et al., 1999). Na coupled L-glutamine transport tends to be higher in the jejunum of piglets supplemented with Enterococcus faecium NCIMB 10415 (Lodemann et al., 2006) and Bacillus cereus var. toyoi (Lodemann et al., 2008).

Lactobacillus acidophilus increases the expression of the apical anion exchanger SLC26A3 and thereby stimulates $\mathrm{Cl} / \mathrm{OH}$ exchange activity affecting the electrolyte absorption (Raheja et al., 2010).

Vinderola et al. showed that the expression of the main calcium transporter in the intestinal epithelial cells, TRPV6, was enhanced in the duodenum of mice treated with supernatant of milk fermented by Lactobacillus helveticus R389 (Vinderola et al., 2007). Additionally, components of the intestinal microflora have the ability to enhance expression of the vitamin $D$ receptor in intestinal epithelial cells in SCFA-dependent and -independent manner, thus indirectly affecting the metabolism of calcium (Resta, 2009).

Huang et al. showed that Lactobacillus acidophilus ATCC 4356 decreased gene expression of NiemannPick C1-like 1 (NPC1L1), a recently identified protein that is involved in cholesterol absorption, and consequently inhibited the cellular uptake of micellar cholesterol in Caco2 cells. They suggested that soluble effector molecules secreted by ATCC 4356 were responsible for that effect (Huang and Zheng, 2010). Similar results were observed in vivo where the expression of NPC1L1 protein in duodenum and jejunum of probiotic-treated rats was significantly reduced (Huang et al., 2010). These findings suggest that NPC1L1 might be responsible for hypocholesterolemic activity of probiotics besides other well-known mechanisms involved in this process such as enzymatic deconjugation of bile acids by bile salt hydrolase (BSH), cholesterol binding to cell walls of probiotics, assimilation, and incorporation of cholesterol into the cellular membranes of bacteria, conversion of cholesterol into coprostanol, co-precipitation of cholesterol with deconjugated bile acids, and production of SCFA (Pavlovic et al., 2012).

Furthermore, it is interesting to mention the potential of using probiotics to controlled delivery of desired molecules directly to target sites within a host (Behnsen et al., 2013). Some probiotic strains, such as Lactococcus lactis, which is a good candidate for the production of biologically useful proteins (Nouaille et al., 2003), has emerged as a potential delivery vehicles for various antigens as well as therapeutic and immunomodulatory proteins (Bahey-El-Din and Gahan, 2010). These strains are used as delivery vehicles for protein vaccines and even, DNA vaccines directly to the mucosa. The use of probiotics to deliver cytokines directly to target sites can be applied to treat some diseases such as IBD (Behnsen et al., 2013), which is associated with a shift of balance from secretion of anti-inflammatory mediators towards pro-inflammatory molecules and a weakened integrity of the epithelial barrier (Stojancevic et al., 2012). Accordingly, it has been demonstrated that IL-10producing Lactococcus lactis strain and Lactococcus lactis engineered to produce anti-TNF- $\alpha$ nanobodies markedly reduced colonic inflammation and improved colitis in mice (Steidler et al., 2000; Vandenbroucke et al., 2010). This offers novel approach in the treatment of IBD avoiding the disadvantages associated with systemic administration (Bahey-El-Din and Gahan, 2010).

Beside affecting microbial enzymes in intestinal tract, it is highly likely that the exposure to probiotics could well influence the drug metabolism via induction of various cytochrome P450s or phase II conjugating enzymes in gut, which are responsible for their metabolism (Wilson and Nicholson, 2009). In a recently conducted study, the oral application of Lactobacillus casei caused the decreased expression of CYP1A1 protein in the jejunum and colon of the experimental animal. Additionally, level of CYP3A9 in duodenum was found to be decreased as well (Matuskova et al., 2011).

The one more possible way how probiotics may alter drug bioavailability, is to affect the expression of intestinal transporters that are involved in drug transport across the intestinal wall. Findings by Saksena et al. suggested 
that Lactobacilli or their soluble factors significantly enhanced P-gp expression and function under normal and inflammatory conditions (Saksena et al., 2011). This could be of considerable importance in the disposition of drugs which are substrates of this transporter. Al Salami et al. observed that probiotic treatment reduced gliclazide absorption and bioavailability in healthy rats whereas it exerted the opposite effect in diabetic rats. They explain it by the fact that in healthy rats, bacterial metabolites may activate the intestinal efflux drug transporter MRP2, which control gliclazide transport, but cannot overcome the impairment of MRP2 that is present in diabetic rats. Another possible explanation is the suppressing the expression of MRP3 by probiotics, causing less gliclazide being removed from the ileal enterocytes into the blood leading to decrease in the net gliclazide absorption. The suggested mechanism may also be formation of a 'thicker' layer of the adherent mucous, which supports the physical barrier protecting the enterocytes. Another possible reason includes bacterial enzymatic degradation of gliclazide, although the bacterial metabolism of gliclazide has not been proved yet (AI Salami et al., 2008). Furthermore, they investigated if probiotics influence on monoketocholate (MKC) pharmacokinetics when MKC is administered orally with gliclazide to diabetic rats. As with gliclazide, the reduction in the bioavailability of MKC by probiotic pretreatment of healthy rats may be explained by probiotics inducing increased presystemic metabolism and stimulating bacterial degradation of MKC. The decrease in MKC bioavailability, when administered with gliclazide, caused by probiotic treatment in healthy but not diabetic rats suggests that probiotic treatment induced MKC metabolism or impaired its absorption, only in healthy animals) (Al Salami et al., 2012a).

What kind of effects a certain probiotic strain exhibits depends on its metabolic properties, the kind of surface molecules expressed or on the components secreted. Considering that proposed mechanisms of probiotic actions are the mostly results of in vitro experiments, they must be confirmed by in vivo studies (Oelschlaeger, 2010).

\section{Conclusions}

This review highlights the vital role of the intestinal microflora, intestinal and bacterial transporters and enzymes in determining the fate of drugs in the host, showing that they may alter the pharmacokinetic profile of drugs leading to increased toxicity, altered efficacy of the drug, increased production of toxic metabolites, and adverse drug interactions. Although the intestinal microflora has been mostly studied in the context of host health benefit, it has recently become clear that this microbial community has an important role in drug metabolism by providing additional enzymatic activities involved in the transformation of drugs. Consumption of probiotics is able to modulate the composition and metabolic activity of the intestinal microflora, as well as expression of intestinal enzymes and transporters at various levels, consequently affecting the pharmacological behavior of a vast number of drugs in use today. It is important to note that each probiotic strain has its own specific properties. Although the field of probiotic research has grown significantly, this still remains a great challenge for researchers. Beside large variety of probiotic species and strains, also different dosages are used, as well as combinations of probiotics and prebiotics, thus hinder the comparison of results from different groups. Deepening our knowledge in that domain, we will be in a better position to predict the behavior of drug and to optimize the therapy for patient, since the presence of bacterial community in the intestine and its metabolic activity and transporters may be linked with inter- and intra-individual differences in drug metabolism. This is a reason why appropriate consideration of individual human gut microbial composition and activity will be a necessary part of future personalized healthcare.

\section{Acknowledgements}

This work is supported by Ministry of Education, Science and Technological Development, Republic of Serbia, project No. 41012.

\section{References}

Ahmed, M., Lyass, L., Markham, P.N., Taylor, S.S., Vázquez-Laslop, N., and Neyfakh, A.A. (1995). Two highly similar multidrug transporters of Bacillus subtilis whose expression is differentially regulated. J. Bacteriol. 177, 3904-3910.

Al-Salami, H., Butt, G., Fawcett, J.P., Tucker, I.G., Golocorbin-Kon, S., and Mikov, M. (2008). Probiotic treatment reduces blood glucose levels and increases systemic absorption of gliclazide in diabetic rats. Eur $\mathrm{J}$ Drug Metab Pharmacokinet. 33, 101-106.

Al-Salami, H., Butt, G., Tucker, I., Golocorbin-Kon, S., and Mikov, M. (2012a). Probiotics decreased the bioavailability of the bile acid analog, monoketocholic acid, when coadministered with gliclazide, in healthy but not diabetic rats. Eur J Drug Metab Pharmacokinet. 37, 99-108.

Al-Salami, H., Caccetta, R., Golocorbin-Kon, S., and Mikov, M. (2012b). Probiotics applications in autoimmune diseases. In Probiotics, E.C. Rigobelo, ed., 325-366. DOI: 10.5772/50463. http://www.intechopen.com/ books/probiotics/probiotics-applications-in-autoimmunediseases

Bahey-El-Din, M., and Gahan, C.G. (2010). Lactococcus lactis: from the dairy industry to antigen and therapeutic protein delivery. Discov. Med. 9, 455-461.

Bailey, D.G., Spence, J.D., Munoz, C., and Arnold, J.M. (1991). Interaction of citrus juices with felodipine and nifedipine. Lancet. 337, 268-269.

Behnsen, J., Deriu, E., Sassone-Corsi, M., and Raffatellu, M. (2013). Probiotics: properties, examples, and specific applications. Cold Spring Harb. Perspect. Med. 3, a010074. doi: 10.1101/cshperspect.a010074.

Bezirtzoglou, E.E.V. (2012). Intestinal cytochromes P450 regulating the intestinal and its probiotic profile. Microb. Ecol. Health D. 23, 18370-http://dx.doi.org/10.3402/ mehd.v23i0.18370

Bourlioux, P., Koletzko, B., Guarner, F., and Braesco, V. (2003). The intestine and its microflora are partners for the protection of the host: report on the Danone Symposium "The Intelligent Intestine," held in Paris, June 14, 2002. Am. J. Clin. Nutr. 78, 675-683.

Burns, A.J., and Rowland, I.R. (2000). Anti-carcinogenicity of probiotics and prebiotics. Curr Issues Intest. Microbiol. 1, 13-24.

Buts, J., De Keyser, N., Marandi, S., Hermans, D., Sokal, E., Chae, Y., Lambotte, L., Chanteux, H., and Tulkens, P. (1999). Saccharomyces boulardii upgrades cellular adaptation after proximal enterectomy in rats. Gut. 45, 
89-96.

Buts, J.P., and De Keyser, N. (2006). Effects of Saccharomyces boulardii on intestinal mucosa. Dig. Dis. Sci. 51, 1485-1492.

Cole, C.B., Fuller, R., and Carter, S.M. (1989). Effect of probiotic supplements of Lactobacillus acidophilus and Bifidobacterium adolescentis on ß-glucosidase and ß-glucuronidase activity in the lower gut of rats associated with a human faecal flora. Microb. Ecol. Health Dis. 2, 223-225.

Conly, J.M., and Stein, K. (1992). The production of menaquinones (vitamin K2) by intestinal bacteria and their role in maintaining coagulation homeostasis. Prog. Food. Nutr. Sci. 16, 307-343.

Clemente, J.C., Ursell, L.K., Parfrey, L.W., and Knight, R. (2012) The impact of the gut microbiota on human health: an integrative view. Cell. 148, 1258-1270.

Davidson, A.L., and Chen, J. (2004). ATP-binding cassette transporters in bacteria. Annu. Rev. Biochem. 73, 241268.

De Preter, V., Hamer, H.M., Windey, K., and Verbeke, K. (2011). The impact of pre- and/or probiotics on human colonic metabolism: Does it affect human health? Mol. Nutr. Food Res. 55, 46-57.

Deferme, S., Annaert, P., and Augustijns, P. (2008) In Vitro Screening Models to Assess Intestinal Drug Absorption and Metabolism. In Situ, In Vitro and In Silico Models. In Drug absorption studies. Biotechnology: pharmaceutical aspects, E. Carsten and K. Kwang-Jin, eds. (Springer, US), pp. 182-215.

Delcenserie, V., Martel, D., Lamoureux, M., Amiot, J., Boutin, Y., and Roy, D. (2008). Immunomodulatory effects of probiotics in the intestinal tract. Curr. Issues Mol. Biol. 10, 37-54.

Dresser, G.K., Spence, J.D., and Bailey, D.G. (2000) Pharmacokinetic-pharmacodynamic consequences and clinical relevance of cytochrome P450 3A4 inhibition. Clin Pharmacokinet. 38, 41-57.

Elmer, G.W., and Remmel, R.P. (1984). Role of the intestinal microflora in clonazepam metabolism in the rat. Xenobiotica. 14, 829-840.

Englund, G., Rorsman, F., Rönnblom, A., Karlbom, U., Lazorova, L., Gråsjö, J., Kindmark, A., and Artursson, P. (2006). Regional levels of drug transporters along the human intestinal tract: Co-expression of $A B C$ and SLC transporters and comparison with Caco-2 cells. Eur. J. Pharm. Sci. 29, 269-277.

Estudante, M., Morais, J.G., Soveral, G., and Benet, L.Z. (2012). Intestinal drug transporters: An overview. Adv. Drug. Deliv. Rev. pii: S0169-409X(12)00303-1. doi: 10.1016/j.addr.2012.09.042.

Ferreira, C.L., Salminen, S., Grzeskowiak, L., Brizuela, M.A., Sanchez, L., Carneiro, H, and Bonnet, M. (2011). Terminology concepts of probiotic and prebiotic and their role in human and animal health. Rev. Salud. Anim. 33, 137-146.

Fooks, L.J. and Gibson, G.R. (2002). Probiotics as modulators of the gut flora. Br. J. Nutr. 88, S39-S49.

Fromm, M.F., Busse, D., Kroemer, H.K., and Eichelbaum, M. (1996). Differential induction of prehepatic and hepatic metabolism of verapamil by rifampin. Hepatology 24 , 796-801.

Furfine, E.S., Baker, C.T., Hale, M.R., Reynolds, D.J.,
Salisbury, J.A., Searle, A.D., Studenberg, S.D., Todd, D., Tung, R.D., and Spaltenstein, A. (2004). Preclinical pharmacology and pharmacokinetics of GW433908, a water-soluble prodrug of the human immunodeficiency virus protease inhibitor amprenavir. Antimicrob. Agents Chemother. 48, 791-8.

Gareau, M.G., Sherman, P.M., and Walker, W.A. (2010). Probiotics and the gut microbiota in intestinal health and disease. Nat. Rev. Gastroenterol. Hepatol. 7, 503-514.

Gavhanea, Y.N., and Yadav, A.V. (2012). Loss of orally administered drugs in GI tract. Saudi Pharm. J. 20, 331344.

Gerritsen, J., Smidt, H., Rijkers, G.T., and de Vos, W.M. (2011). Intestinal microbiota in human health and disease: the impact of probiotics. Genes Nutr. 6, 209-240.

Giacomini, K.M., Huang, S.M., Tweedie, D.J., Benet, L.Z., Brouwer, K.L., Chu, X., Dahlin, A., Evers, R., Fischer, V., Hillgren, K.M., Hoffmaster, K.A., Ishikawa, T., Keppler, D., Kim, R.B., Lee, C.A., Niemi, M., Polli, J.W., Sugiyama, Y., Swaan, P.W., Ware, J.A., Wright, S.H., Yee, S.W., ZamekGliszczynski, M.J., and Zhang, L. (2010). Membrane transporters in drug development. Nat. Rev. Drug. Discov. 9, 215-236. doi: 10.1038/nrd3028.

Gibson, G.R., and Roberfroid, M.B. (1995). Dietary modulation of the human colonic microbiota: introducing the concept of prebiotics. J. Nutr. 125, 1401-1412.

Gillor, O., Etzion, A., and Riley, M.A. (2008). The dual role of bacteriocins as anti- and probiotics Appl. Microbiol. Biotechnol, 81, 591-606.

Goldin, B.R. (1990). Intestinal Microflora: Metabolism of Drugs and Carcinogens. Ann. Med. 22, 43-48.

Goldin, B.R., and Gorbach, S.L. (1984). The effect of milk and lactobacillus feeding on human intestinal bacterial enzyme activity. Am. J. Clin. Nutr. 39, 756-761.

Goossens, D., Jonkers, D., Russel, M., Stobberingh, E., Van Den Bogaard, A., and Stockbrügger, R. (2003). The effect of Lactobacillus plantarum 299 on the bacterial composition and metabolic activity in faeces of healthy volunteers: a placebo-controlled study on the onset and duration of effects. Aliment. Pharmacol. Ther. 18, 495505.

Grkovic, S., Brown, M.H., and Skurray, R.A. (2002). Regulation of bacterial drug export systems. Microbiol. Mol. Biol. Rev. 66, 671-701.

Grundmann, O. (2010). The gut microbiome and presystemic metabolism: current state and evolving research. J. Drug Metab. Toxicol. 1, 104. doi:10.4172/21577609.1000104

Holt, R. (1967). The bacterial degradation of chloramphenicol. Lancet. 1, 1259-1260.

Houston, J.B., Day, J., and Walker J. (1982). Azo reduction of sulphasalazine in healthy volunteers. $\mathrm{Br}$. J. Clin. Pharmacol. 14, 395-398.

Huang, Y., and Zheng, Y. (2010). The probiotic Lactobacillus acidophilus reduces cholesterol absorption through the down-regulation of Niemann-Pick C1-like 1 in Caco-2 cells. Br. J. Nutr. 103, 473-478.

Huang, Y., Wang, J., Cheng, Y., and Zheng, Y. (2010). The hypocholesterolaemic effects of Lactobacillus acidophilus American type culture collection 4356 in rats are mediated by the down-regulation of Niemann-Pick C1-like 1. Br. J. Nutr. 104, 807-812.

lannitti, T., and Palmieri, B (2010). Therapeutical use of 
probiotic formulations in clinical practice. Clin. Nutr. 29, 701-725.

Ilett, K.F., Tee, L.B., Reeves, P.T., and Minchin, R.F. (1990). Metabolism of drugs and other xenobiotics in the gut lumen and wall. Pharmacol. Ther. 46, 67-93.

Imai, T., Imoto, M., Sakamoto, H., and Hashimoto, M. (2005). Identification of esterases expressed in Caco-2 cells and effects of their hydrolyzing activity in predicting human intestinal absorption. Drug Metab. Dispos. 33, 1185-1190.

Joint FAO/WHO Working Group. Guidelines for the evaluation of probiotics in food: report of a Joint FAO/WHO Working Group on Drafting Guidelines for the Evaluation of Probiotics in Food, London, Ontario, Canada. (2002). Available at: http://www.who.int/foodsafety/publications/ fs_management/probiotics2/en/index.html.

Kim, R.B. (2006). Transporters and drug discovery: why, when, and how. Mol. Pharm. 3, 26-32.

Kim, Y., Lee, D., Kim, D., Cho, J., Yang, J., Chung, M., Kim, K., and Ha, N. (2008). Inhibition of proliferation in colon cancer cell lines and harmful enzyme activity of colon bacteria by Bifidobacterium adolescentis SPM0212. Arch. Pharm. Res. 31, 468-473.

Kitamura, S., Sugihara, K., Kuwasako, M., and Tatsumi, K. (1997). The role of mammalian intestinal bacteria in the reductive metabolism of zonisamide. J. Pharm. Pharmacol. 49, 253-256.

Kivistö, K.T., Niemi, M., and Fromm, M.F. (2004). Functional interaction of intestinal CYP3A4 and P-glycoprotein. Fundam. Clin. Pharmacol. 18, 621-626.

Kleerebezem, M., and Vaughan, E.E. (2009). Probiotic and gut lactobacilli and bifidobacteria: molecular approaches to study diversity and activity. Annu. Rev. Microbiol. 63, 269-290.

Koch, R.L., and Goldman, P. (1979). The anaerobic metabolism of metronidazole forms $\mathrm{N}$-(2-hydroxyethyl)oxamic acid. J. Pharmacol. Exp. Ther. 208, 406-410.

Kourtesi, C., Ball, A.R., Huang, Y.Y., Jachak, S.M., Vera, D.M., Khondkar, P., Gibbons, S., Hamblin, M.R., and Tegos, G.P. (2013). Microbial efflux systems and inhibitors: approaches to drug discovery and the challenge of clinical implementation. Open Microbiol. J. 7, 34-52.

Krishna, D.R., and Klotz, U. (1994). Extrahepatic metabolism of drugs in humans. Clin. Pharmacokinet. 26, 144-160.

Laparra, J.M., and Sanz, Y. (2010). Interactions of gut microbiota with functional food components and nutraceuticals. Pharmacol. Res. 61, 219-225.

Laube, B., Winkler, S., Ladstetter, B., Scheller, T., and Schwarz, L.R. (2000). Establishment of a novel in vitro system for studying the interaction of xenobiotic metabolism of liver and intestinal microflora. Arch. Toxicol. 74, 379-387.

Lee, H.J., Zhang, H., Orlovich, D.A., and Fawcett, J.P. (2012). The influence of probiotic treatment on sulfasalazine metabolism in rat. Xenobiotica. 42, 791-797.

Lee, Y.H., Perry, B.A., Lee, H.S., Kunta, J.R., Sutyak, J.P., and Sinko, P.J. (2001). Differentiation of gut and hepatic first-pass effect of drugs: 1 . Studies of verapamil in ported dogs. Pharm. Res. 18, 1721-1728.

Lennernäs, H. (2010) Animal Perfusion Studies. In (eds.). Oral drug absorption prediction and assessment. J.B. Dressman, H. Lennernäs, eds. (New York: Marcel Dekker Inc), pp. 73-98.
Lenoir-Winjnkoop, I., and Hopkins, M. (2003). The intestinal microflora. Understanding the symbiosis. D. Vitapole, ed. (Montrouge, France: John Libbey Eurotext).

Li, J., and Hidalgo, I.J. (1996). Molecular modeling study of structural requirements for the oligopeptide transporter. J. Drug Target. 4, 9-17.

Li, X.Z., and Nikaido, H. (2009). Efflux-mediated drug resistance in bacteria: an update. Drugs. 69, 1555-1623.

Lodemann, U., Hübener, K., Jansen, N., and Martens, H. (2006). Effects of Enterococcus faecium NCIMB 10415 as probiotic supplement on intestinal transport and barrier function of piglets. Arch. Anim. Nutr. 60, 35-48.

Lodemann, U., Lorenz, B.M., Weyrauch, K.D., and Martens, H. (2008). Effects of Bacillus cereus var. toyoi as probiotic feed supplement on intestinal transport and barrier function in piglets. Arch. Anim. Nutr. 62, 87-106.

Löfmark, S., Edlund, C., and Nord, C.E. (2010). Metronidazole is still the drug of choice for treatment of anaerobic infections. Clin. Infect. Dis. 50, S16-S23.

Mallett, A.K., Bearne, C.A., and Rowland, I.R. (1989). The influence of incubation $\mathrm{pH}$ on the activity of rat and human gut flora enzymes. J. Appl. Bacteriol. 66, 433-437.

Margolles, A., Flórez, A.B., Moreno, J.A., van Sinderen, D., and de los Reyes-Gavilán, C.G. (2006). Two membrane proteins from Bifidobacterium breve UCC2003 constitute an ABC-type multidrug transporter. Microbiology. 152, 3497-3505.

Marik, P.E. (2012). Colonic flora, probiotics, obesity and diabetes. Front. Endocrinol. (Lausanne). 3, 87. doi: 10.3389/fendo.2012.00087.

Martinez, M.N., and Amidon, G.L. (2002). A mechanistic approach to understanding the factors affecting drug absorption: a review of fundamentals. J. Clin. Pharmacol. 42, 620-643.

Masaki, K., Hashimoto, M., and Imai, T. (2007). Intestinal first-pass metabolism via carboxylesterase in rat jejunum and ileum. Drug. Metab. Dispos. 35, 1089-1095.

Mathur, S., and Singh, R. (2005). Antibiotic resistance in food lactic acid bacteria-a review. Int. J. Food Microbiol. 105, 281-295.

Matuskova, Z., Siller, M., Tunkova, A., Anzenbacherova, E., Zacharova, A., Tlaskalova-Hogenova, H., Zidek, Z., and Anzenbacher, P. (2011). Effects of Lactobacillus casei on the expression and the activity of cytochromes P450 and on the CYP mRNA level in the intestine and the liver of male rats. Neuro Endocrinol. Lett. 32, 8-14.

Mikov, M. (1994). The metabolism of drugs by the gut flora. Eur. J. Drug Metab. Ph. 19, 201-207.

Mikov, M., Lee, H.J., Fawcett, J.P. (2006). The influence of probiotic treatment on sulfasalazine metabolism in rat gut contents. Asian J. Pharmacokinet. Pharmacodyn. 6, 337342.

Nitzan, O., Suponitzky, U., Kennes, Y., Chazan, B., Raul, R., and Colodner, R. (2010). Is chloramphenicol making a comeback? Isr. Med. Assoc. J. 12, 371-374.

Nouaille, S., Ribeiro, L.A., Miyoshi, A., Pontes, D., Le Loir, Y., Oliveira, S.C., Langella, P., and Azevedo, V. (2003). Heterologous protein production and delivery systems for Lactococcus lactis. Genet. Mol. Res. 2, 102-111.

Oelschlaeger, T.A. (2010). Mechanisms of probiotic actions - A review. Int. J. Med. Microbiol. 300, 57-62.

Oostendorp, R.L., Beijnen, J.H., and Schellens, J.H. (2009). The biological and clinical role of drug transporters at the 
intestinal barrier. Cancer Treat. Rev. 35, 137-147.

Orelle, C., Dalmas, O., Gros, P., di Pietro, A. and Jault, J. M. (2003). The conserved glutamate residue adjacent to the Walker-B motif is the catalytic base for ATP hydrolysis in the ATP-binding cassette transporter BmrA. J. Biol. Chem. 278, 47002-47008.

Orrhage, K., and Nord, C.E. (2000). Bifidobacteria and lactobacilli in human health. Drugs Exp. Clin. Res. 26, 95-111.

Pang, K.S. (2003). Modeling of intestinal drug absorption: roles of transporters and metabolic enzymes (for the Gillette Review Series). Drug Metab. Dispos. 31, 15071519.

Paulsen, I.T., Chen, J., Nelson, K.E., and Saier MH Jr. (2001). Comparative genomics of microbial drug efflux systems J. Mol. Microbiol. Biotechnol., 3, 145-150.

Pavlović, N., Stankov, K., and Mikov, M. (2012). Probioticsinteractions with bile acids and impact on cholesterol metabolism. Appl. Biochem. Biotechnol. 168, 1880-1895.

Perreten, V., Schwarz, F.V., Teuber, M., and Levy, S.B. (2001). $\operatorname{Mdt}(A)$, a new efflux protein conferring multiple antibiotic resistance in Lactococcus lactis and Escherichia coli. Antimicrob. Agents Chemother. 45, 1109-1114.

Putman, M., van Veen, H.W., and Konings, W.N. (2000). Molecular properties of bacterial multidrug transporters. Microbiol. Mol. Biol. Rev. 64, 672-693.

Rabot, S., Rafter, J., Rijkers, G.T., Watzl, B., and Antoine, J.M. (2010). Guidance for substantiating the evidence for beneficial effects of probiotics: impact of probiotics on digestive system metabolism. J. Nutr. 140, 677S-689S.

Raheja, G., Singh, V., Ma, K., Boumendjel, R., Borthakur, A., and Gill, R.K., Saksena, S., Alrefa, W.A., Ramaswamy, K., and Dudeja, P.K. (2010). Lactobacillus acidophilus stimulates the expression of SLC26A3 via a transcriptional mechanism. Am. J. Physiol. Gastrointest. Liver Physiol. 298, G395-G401.

Resta, S.C. (2009). Effects of probiotics and commensals on intestinal epithelial physiology: implications for nutrient handling. J. Physiol. 587, 4169-4174.

Riley, M.A., and Wertz, J.E. (2002). Bacteriocins: evolution, ecology, and application. Annu. Rev. Microbiol. 56, 117137.

Rowland, I.R. (1988). Interactions of the gut microflora and the host in toxicology. Toxicol. Pathol. 16, 147-153.

Saha, J.R., Butler, V.P. Jr., Neu, H.C., and Lindenbaum J. (1983). Digoxin-inactivating bacteria: identification in human gut flora. Science. 220, 325-327.

Sakamoto, K., Margolles ${ }_{\perp}$ A., van Veen ${ }_{\perp}$ H.W., and Konings, W.N. (2001). Hop resistance in the beer spoilage bacterium Lactobacillus brevis is mediated by the ATP. binding cassette multidrug transporter HorA. J. Bacteriol. 183, 5371-5375.

Saksena, S., Goyal, S., Raheja, G., Singh, V., Akhtar, M., Nazir, T.M., Alrefai, W.A., Gill, R.K., and Dudeja, P.K. (2011). Upregulation of P-glycoprotein by probiotics in intestinal epithelial cells and in the dextran sulfate sodium model of colitis in mice. Am J. Physiol. Gastrointest. Liver Physiol. 300, G1115-G1123.

Sastry, S.V., Nyshadham, J.R., and Fix, J.A. (2000). Recent technological advances in oral drug delivery - a review. Pharm. Sci. Technol. Today. 3, 138-145.

Schinkel, A.H., and Jonker, J.W. (2003). Mammalian drug efflux transporters of the ATP binding cassette (ABC) family: an overview. Adv. Drug. Deliv. Rev. 55, 3-29.

Sekirov, I., Russell, S.L., Antunes, L.C.M., and Finlay, B.B. (2010). Gut microbiota in health and disease. Physiol. Rev. 90, 859-904.

Sharom, F.J. (2008). ABC multidrug transporters: structure, function and role in chemoresistance. Pharmacogenomics. 9, 105-127.

Sousa, T.,Paterson, R., Moore, V., Carlsson,A.,Abrahamsson, B., and Basit, A.W. (2008). The gastrointestinal microbiota as a site for the biotransformation of drugs. Int. J. Pharm. $363,1-25$.

Spanhaak, S., Havenaar, R., and Schaafsma, G. (1998). The effect of consumption of milk fermented by Lactobacillus casei strain Shirota on the intestinal microflora and immune parameters in humans. Eur. J. Clin. Nutr. 52, 899-907.

Stain-Texier, F., Sandouk, P., and Scherrmann, J.M. (1998). Intestinal absorption and stability of morphine 6-glucuronide in different physiological compartments of the rat. Drug Metab. Dispos. 26, 383-387.

Steidler, L., Hans, W., Schotte, L., Neirynck, S., Obermeier, F., Falk, W., Fiers, W., and Remaut, E. (2000). Treatment of murine colitis by Lactococcus lactis secreting interleukin-10. Science. 289, 1352-1355.

Stojancevic, M., Stankov, K., and Mikov, M. (2012). The impact of farnesoid $X$ receptor acivation on intestinal permeability in inflammatory bowel disease. Can. J. Gastroenterol. 26, 631-637.

Strojný, L., Bomba, A., Hijová, E., Chmelárová, A., Mojžišová, G., Bertková, I., Koprovičová, J., Pomfy, M., Strompfová, V., and Molokáčová, M. (2011) Effects of a probiotic in combination with prebiotics on intestinal lactobacilli and coliforms and activities of bacterial enzymes in 1,2-dimethylhydrazine exposed rats. Czech J. Anim. Sci. 56, 99-106.

Strong, H.A., Oates, J., Sembi, J., Renwick, A.G., and George, C.F. (1984). Role of the gut flora in the reduction of sulfinpyrazone in humans. J. Pharmacol. Exp. Ther. 230, 726-732.

Sugiura, T., Kato, Y., and Tsuji, A. (2006). Role of SLC xenobiotic transporters and their regulatory mechanisms PDZ proteins in drug delivery and disposition. J. Control. Release. 116, 238-246.

Suskovic, J., Kos, B., Beganovic, J., Lebos Pavunc, A., Habjanic, K., and Matosic, S. (2010). Antimicrobial activity - the most important property of probiotic and starter lactic acid bacteria. Food Technol. Biotechnol. 48, 296-307.

Swann, J.R., Want, E.J., Geier, F.M., Spagou, K., Wilson, I.D., and Sidaway, J.E., Nicholson JK, Holmes E. (2011). Systemic gut microbial modulation of bile acid metabolism in host tissue compartments. Proc. Natl. Acad. Sci. U S A. 108, 4523-4530.

Szakács, G., Váradi, A., Özvegy-Laczka, C., and Sarkadi, B. (2008). The role of $A B C$ transporters in drug absorption, distribution, metabolism, excretion and toxicity (ADMETox). Drug Discov. Today. 13, 379-393.

Takeno, S., and Sakai, T. (1991). Involvement of the intestinal microflora in nitrazepam-induced teratogenicity in rats and its relationship to nitroreduction. Teratology. 44, 209-214.

Thelen, K., and Dressman, J.B. (2009). Cytochrome P450mediated metabolism in the human gut wall. J. Pharm. Pharmacol. 61, 541-558. 
Thummel, K.E., O'Shea, D., Paine, M.F., Shen, D.D., Kunze, K.L., Perkins, J.D., and Wilkinson, G.R. (1996). Oral first-pass elimination of midazolam involves both gastrointestinal and hepatic CYP3A-mediated metabolism. Clin. Pharmacol. Ther. 59, 491-502.

Torres, C., Galián, C., Freiberg, C., Fantino, J.R., and Jault, J.M. (2009). The Yhel/YheH heterodimer from Bacillus subtilis is a multidrug $A B C$ transporter. Biochim. Biophys. Acta. 1788, 615-622.

Ünsalan, S., Çıkla, P., Küçükgüzel, Ş.G., Rollas, S., Şahin, F., and Bayrak, Ö.F. (2011). Synthesis and characterization of triazenes derived from sulfonamides. Marmara Pharm. J. 15, 11-17.

van Veen, H. W., Margolles, A., Muller, M., Higgins, C. F. and Konings, W. N. (2000). The homodimeric ATPbinding cassette transporter LmrA mediates multidrug transport by an alternating two-site (twocylinder engine) mechanism. EMBO J. 19, 2503-2514.

Vandenbroucke, K., de Haard, H., Beirnaert, E., Dreier, T., Lauwereys, M., Huyck, L., Van Huysse, J., Demetter, P., Steidler, L., Remaut, E., Cuvelier, C., and Rottiers, P. (2010). Orally administered $L$. lactis secreting an anti-TNF nanobody demonstrate efficacy in chronic colitis. Mucosal Immunol. 3, 49-56.

Vinderola, G., Matar, C., and Perdigón, G. (2007). Milk fermentation products of $\mathrm{L}$. helveticus R389 activate calcineurin as a signal to promote gut mucosal immunity. BMC Immunol. 8, 19. doi:10.1186/1471-2172-8-19

Wacher, V.J., Salphati, L., and Benet, L.Z. (2001) Active secretion and enterocytic drug metabolism barriers to drug absorption. Adv. Drug. Deliv. Rev. 46, 89-102.

Wallace, T.C., Guarner, F., Madsen, K., Cabana, M.D., Gibson, G., Hentges, E., and Sanders, M.E. (2011). Human gut microbiota and its relationship to health and disease. Nutr. Rev. 69, 392-403.

Wilson, I.D., and Nicholson, J.K. (2009). The role of gut microbiota in drug response. Curr. Pharm. Des. 15, 15191523.

Wire, M.B., Shelton, M.J., and Studenberg, S. (2006). Fosamprenavir: clinical pharmacokinetics and drug interactions of the amprenavir prodrug. Clin. Pharmacokinet. 45, 137-168.

Wu, C.Y., Benet, L.Z., Hebert, M.F., Gupta, S.K., Rowland, M., Gomez, D.Y., and Wacher, V.J. (1995). Differentiation of absorption and first-pass gut and hepatic metabolism in humans: studies with cyclosporine. Clin. Pharmacol. Ther. 58, 492-497.

Yan, F., Cao, H., Cover, T.L., Whitehead, R., Washington, M.K., and Polk, D.B. (2007). Soluble proteins produced by probiotic bacteria regulate intestinal epithelial cell survival and growth. Gastroenterology. 132, 562-575. 


\section{Further Reading}

Caister Academic Press is a leading academic publisher of advanced texts in microbiology, molecular biology and medical research. Full details of all our publications at caister.com

- MALDI-TOF Mass Spectrometry in Microbiology Edited by: M Kostrzewa, S Schubert (2016) www.caister.com/malditof

- Aspergillus and Penicillium in the Post-genomic Era Edited by: RP Vries, IB Gelber, MR Andersen (2016) www.caister.com/aspergillus2

- The Bacteriocins: Current Knowledge and Future Prospects Edited by: RL Dorit, SM Roy, MA Riley (2016)

www.caister.com/bacteriocins

- Omics in Plant Disease Resistance Edited by: V Bhadauria (2016) www.caister.com/opd

- Acidophiles: Life in Extremely Acidic Environments Edited by: R Quatrini, DB Johnson (2016) www.caister.com/acidophiles

- Climate Change and Microbial Ecology: Current Research and Future Trend

Edited by: J Marxsen (2016)

www.caister.com/climate

- Biofilms in Bioremediation: Current Research and Emerging Technologies

Edited by: G Lear (2016)

www.caister.com/biorem

- Microalgae: Current Research and Applications Edited by: MN Tsaloglou (2016) www.caister.com/microalgae

- Gas Plasma Sterilization in Microbiology: Theory, Applications, Pitfalls and New Perspectives Edited by: H Shintani, A Sakudo (2016) www.caister.com/gasplasma

- Virus Evolution: Current Research and Future Directions Edited by: SC Weaver, M Denison, M Roossinck, et al. (2016) www.caister.com/virusevol

- Arboviruses: Molecular Biology, Evolution and Control Edited by: N Vasilakis, DJ Gubler (2016) www.caister.com/arbo

- Shigella: Molecular and Cellular Biology Edited by: WD Picking, WL Picking (2016) www.caister.com/shigella

-Aquatic Biofilms: Ecology, Water Quality and Wastewater Treatment

Edited by: AM Romaní, H Guasch, MD Balaguer (2016)

www.caister.com/aquaticbiofilms

- Alphaviruses: Current Biology

Edited by: S Mahalingam, L Herrero, B Herring (2016)

www.caister.com/alpha

- Thermophilic Microorganisms

Edited by: F Li (2015)

www.caister.com/thermophile
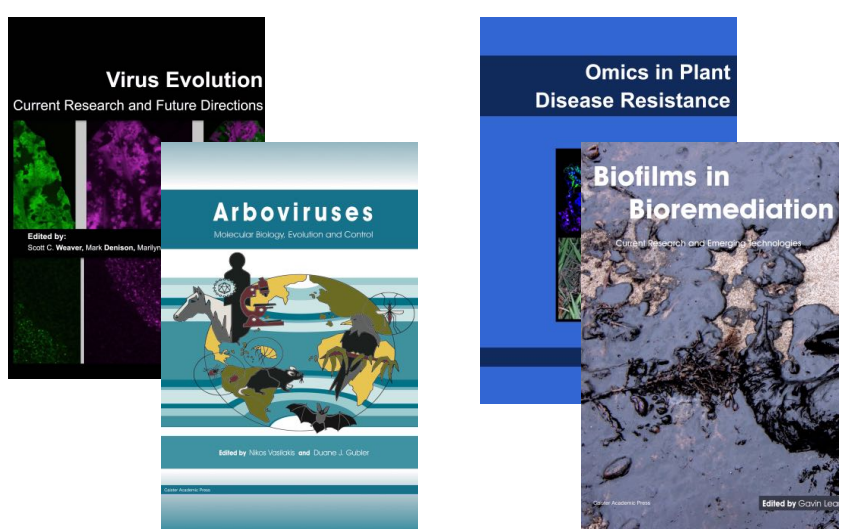
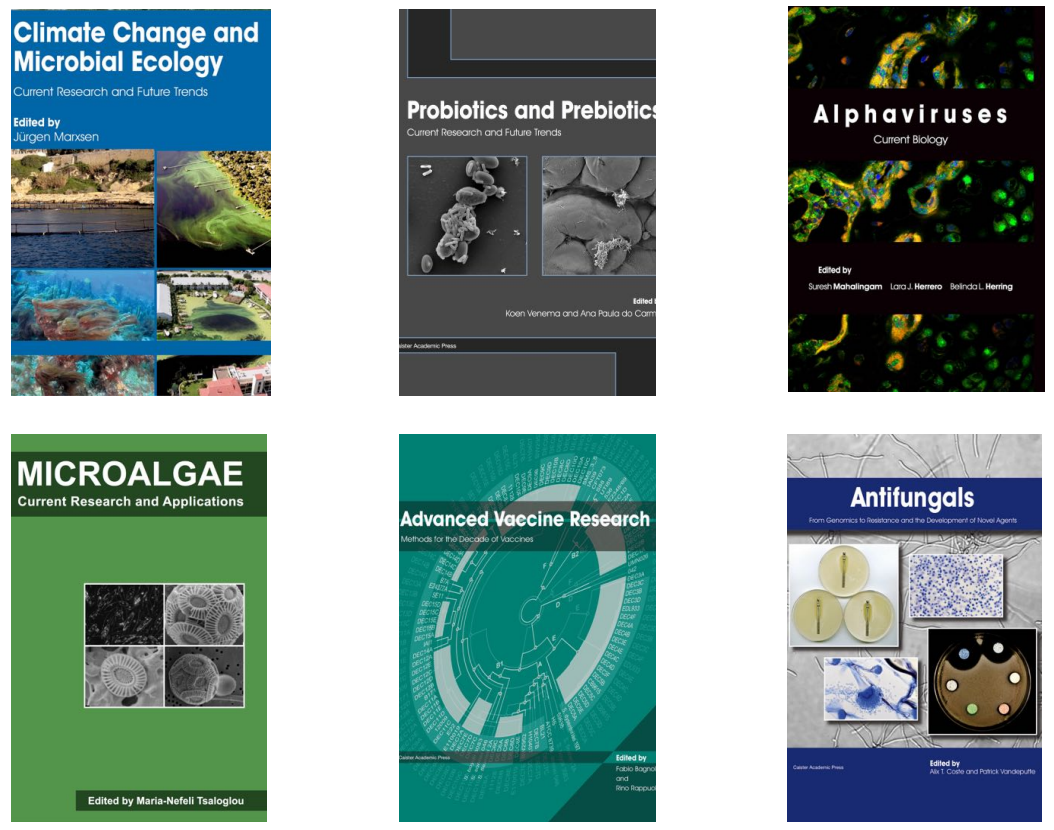

- Flow Cytometry in Microbiology: Technology and Applications Edited by: MG Wilkinson (2015) www.caister.com/flow

- Probiotics and Prebiotics: Current Research and Future Trends Edited by: K Venema, AP Carmo (2015) www.caister.com/probiotics

- Epigenetics: Current Research and Emerging Trends Edited by: BP Chadwick (2015) www.caister.com/epigenetics2015

- Corynebacterium glutamicum: From Systems Biology to Biotechnological Applications

Edited by: A Burkovski (2015)

www.caister.com/cory2

- Advanced Vaccine Research Methods for the Decade of Vaccines

Edited by: F Bagnoli, R Rappuoli (2015)

www.caister.com/vaccines

- Antifungals: From Genomics to Resistance and the Development of Novel Agents

Edited by: AT Coste, P Vandeputte (2015)

www.caister.com/antifungals

- Bacteria-Plant Interactions: Advanced Research and Future Trends Edited by: J Murillo, BA Vinatzer, RW Jackson, et al. (2015) www.caister.com/bacteria-plant

\section{- Aeromonas}

Edited by: J Graf (2015)

www.caister.com/aeromonas

- Antibiotics: Current Innovations and Future Trends

Edited by: S Sánchez, AL Demain (2015)

www.caister.com/antibiotics

- Leishmania: Current Biology and Contro Edited by: S Adak, R Datta (2015) www.caister.com/leish2

- Acanthamoeba: Biology and Pathogenesis (2nd edition) Author: NA Khan (2015)

www.caister.com/acanthamoeba2

- Microarrays: Current Technology, Innovations and Applications Edited by: Z He (2014)

www.caister.com/microarrays2

- Metagenomics of the Microbial Nitrogen Cycle: Theory, Methods and Applications

Edited by: D Marco (2014)

www.caister.com/n2 